\title{
Workers' Perceptions of How Jobs Affect Health: A Social Ecological Perspective
}

\author{
Susan L. Ettner \\ University of California, Los Angeles
}

\author{
Joseph G. Grzywacz \\ University of Northern Iowa
}

\begin{abstract}
A national sample of 2,048 workers was asked to rate the impact of their job on their physical and mental health. Ordered logistic regression analyses based on social ecology theory showed that the workers' responses were significantly correlated with objective and subjective features of their jobs, in addition to personality characteristics. Workers who had higher levels of perceived constraints and neuroticism, worked nights or overtime, or reported serious ongoing stress at work or higher job pressure reported more negative effects. Respondents who had a higher level of extraversion, were self-employed, or worked part time or reported greater decision latitude or use of skills on the job reported more positive effects. These findings suggest that malleable features of the work environment are associated with perceived effects of work on health, even after controlling for personality traits and other sources of reporting bias.
\end{abstract}

Work and health are intimately connected, yet the complex association between multiple features of employment arrangements and workers' health is not well understood. Given the dramatic labor supply and demand changes in the past decade, better identification of the employment characteristics that underlie the health of workers is of profound practical importance. As outlined by the National Occupational Research Agenda (National Institute of Occupational Safety and Health [NIOSH], 1996), the changing nature of jobs (e.g., shift from manufacturing to services) as well as the aging and growing diversity of the workforce suggests that the threats to worker

Susan L. Ettner, Department of Medicine, University of California, Los Angeles (UCLA), School of Medicine, and Department of Health Services, UCLA School of Public Health; Joseph G. Grzywacz, Division of Health Promotion and Health Education, School of Health, Physical Education and Leisure, University of Northern Iowa.

This research was partially supported by a National Institute of Mental Health postdoctoral training grant (MH19958) through the Department of Psychology and Social Behavior at the University of California, Irvine, and the John D. and Catherine T. MacArthur Foundation Research Network on Successful Midlife Development.

We are grateful to Dan Stokols of the University of California, Irvine, for helpful comments on a previous version of this article and members of the John D. and Catherine T. MacArthur Foundation Research Network on Successful Midlife Development, especially Elaine Wethington and Paul Cleary, for helpful suggestions in the early stages of the research.

Correspondence concerning this article should be addressed to Susan L. Ettner, UCLA School of Medicine, Division of General Internal Medicine and Health Services Research, 911 Broxton Plaza, Box 103, Los Angeles, California 90095. Electronic mail may be sent to settner@mednet.ucla.edu. health are dramatically different today than a generation ago. Research examining different aspects of today's jobs and today's workers is therefore necessary to inform employment policies, both at the national level and the employer level, that protect the health of workers.

Although evidence suggests that transitions into unemployment from employment undermine physical health and psychological well-being (for reviews, see Dooley, Fielding, \& Levi, 1996; Kasl, Rodriguez, \& Lasch, 1998; Ross \& Mirowsky, 1995), how jobs affect health among those who remain employed remains less clear. We know that multiple features of the physical, psychological, and social environment of jobs underlie worker health (Jahoda, 1982; Karasek \& Theorell, 1990; Stokols, 1992; Warr, 1994), yet our understanding of the work-health linkage remains circumscribed by theoretical and methodological limitations. For example, although we "know" that physical, psychological, and social aspects of the work environment all affect worker health, there is a general absence of research attempting to use a theoretical framework (e.g., Stokols, 1992) that integrates concepts and propositions from across disciplines and levels of analysis (e.g., Tausig $\&$ Fenwick, 1999). Although discipline-specific research provides important depth (e.g., Feather, 1990), cross-disciplinary linkages in theory and methods offer important new insights that may lead to a more integrative understanding of the phenomenon of interest (Campbell, 1969).

Furthermore, much of the past literature is characterized by two methodological limitations. First, as noted by Ross and Mirowsky (1995) in their review of the unemployment and health literature (p. 240), 
research examining how work affects health has not been able to rule out the possibility of reverse causality or selection effects, that is, that employment is associated with better health because healthy workers are more likely to participate in the labor force and compete successfully for jobs. A similar problem is encountered when examining the influence of job characteristics on health status; for example, an association between "good" jobs and better health may arise simply because healthier workers are better able to get the good jobs. ${ }^{1}$ Second, studies in this area frequently rely exclusively on self-reported, albeit psychometrically sound, measures of job characteristics from survey data (C. E. Haynes, Wall, Bolden, Stride, \& Rick, 1999; Karasek \& Theorell, 1990). Further, although several epidemiological studies have linked self-reported measures of job characteristics to objective health (e.g., myocardial infarction, blood pressure; Curtis, James, Raghunathan, \& Alcser, 1997; Hallqvist et al., 1998; S. G. Haynes, 1980; Karasek et al., 1988; Theorell et al., 1998), little research has examined general health status, which is a more common and salient issue for employers. Unfortunately, measures of general health status from survey databases are by definition also self-reported, so associations of "bad jobs" with "poor health" may be due in part to negativity bias in reporting both job characteristics and health. Similar interpretation problems apply to the estimated relationship between self-reported job characteristics and self-reported medical conditions (e.g., coronary heart disease; Karasek, 1990).

In this study, we use an alternative approach to addressing the question of how work and health are related. By using a methodology with very different strengths and limitations from the existing studies, we seek to provide useful new information regarding this relationship. A national sample of adult workers was asked to rate the impact of their job on their physical and mental health. We examined the associations of their responses with the objective as well as subjective characteristics of their jobs, simultaneously controlling for personality and other individual-level traits thought to influence reporting behavior. By essentially asking workers to conduct the "thought experiment" of what their health would be like in the absence of their jobs, each individual serves as his or her own statistical "control" and the problem of comparing health status across groups of individuals who may be different in unobservable ways is attenuated (see Bronfenbrenner, 1979, p. 27). We situate our study in social ecology theory, using concepts reflecting multiple dimensions and multiple levels of both the individual and the work environment from behavioral models across disciplines.

\section{Theoretical and Empirical Background}

\section{Social Ecology Theory}

Individuals' assessments of how their jobs affect their health can be ascribed to a combination of (a) true health effects of work, the nature of which will depend on the particular attributes of the respondent's job (in conjunction with individual attributes moderating employment effects), and (b) individual attributes leading to differential reporting behavior. Thus, to isolate the influence of work environment, we must control simultaneously for those individual attributes that may skew the reporting of job effects on health.

Social ecology, given its joint focus on both the person and the environment, provides a valuable framework not only for this study but also for advancing our understanding of the complex association between work and health (Stokols, 1992, 1996). For the present study, the social ecological principle of identifying high-impact "leverage points," or factors that exert a disproportionate amount of influence on an outcome (Stokols, 1996), is particularly relevant. Leverage points, identified through theory and research from various fields, can be used to apportion the relative effect of reporting behavior versus actual health effects in examining individuals' responses to questions about how their jobs affect their health.

\section{Health Effects of Work: Individual Characteristics}

Ecological theory of human development would suggest that individuals' dispositions, resources, and characteristics would shape their perceptions of how their jobs influence their health (Bronfenbrenner \& Morris, 1998). Neuroticism, extraversion, and perceived constraints, empirical examples of individual dispositions, would be expected to shape individuals' perceptions of how their job affects their health both directly (through reporting behavior) and because they set into motion relevant person-environment interactions (Bronfenbrenner \& Morris, 1998). As an example of the former, an individual's perceptions of

\footnotetext{
${ }^{1}$ Although in theory, longitudinal analysis can address this limitation, in practice the number of time observations (e.g., Schnall, Schwartz, Landsbergis, Warren, \& Pickering, 1998 ) is usually insufficient to definitively distinguish the direction of causality.
} 
how work affects health may reflect state levels of positive and negative affect; therefore, it is important to adjust for enduring aspects of positive and negative affect (i.e., extraversion and neuroticism). As an example of the latter, hostile individuals (one specific manifestation of neuroticism; Costa \& McRae, 1988) tend to have more conflicted social interactions (Smith, 1992) and may therefore argue more with coworkers, leading to a more negative evaluation of how work affects health.

Although there is debate in the personality literature regarding the relative advantages of the "Big Three" versus the "Big Five" structural models of personality, the common features of both models meet the needs of the present study. (For a discussion, see Watson \& Hubbard, 1996.) We therefore hypothesized that a high level of extraversion would be associated with favorable perceptions of work on health, whereas a high level of neuroticism and constraint would be associated with more negative perceptions of how work influences health.

Individual characteristics and resources give rise to different employment opportunities, as well as different meanings ascribed to employment. For example, women frequently have more choice than men regarding whether to participate in the labor force (Repetti, Matthews, \& Waldron, 1989). Blacks and individuals with a low level of education frequently have difficulty finding and keeping jobs (U.S. Department of Labor, 1999); consequently, these workers are likely to use different criteria in evaluating the health effects of their job. That is, marginalized workers view simply being employed as most relevant to health because the most likely alternative (i.e., unemployment) has clear health disadvantages. Among individuals with relatively secure employment (e.g., those with a high level of education), by contrast, qualitative aspects of work take on greater relevance to health as workers may come to hold higher expectations of their jobs (Jahoda, 1982). Thus, we hypothesized that women, Blacks, and less well-educated workers will report more positive perceptions of how their jobs affect their health.

Warr (1992) speculated that individuals from older cohorts enter the labor force feeling more optimistic about employment than their younger cohort counterparts and may "hold onto" this optimism better. Furthermore, the degree of self-selection into the labor force is probably greater among older than younger individuals, so that the sense of optimism about employment among older workers is reinforced by this selection. Thus, we hypothesized that older workers will report more positive effects of work on health. Finally, because family arrangements and re- sponsibilities may differ systematically by gender and race and may shape perceptions of work-related stress (e.g., role strain; Goode, 1960), marital status and having a young child were also controlled in all analyses.

\section{Health Effects of Work: Employment Characteristics}

A long-standing and rich body of literature examines how work and health are connected; however, most of the vast work-health research falls into three broad categories. The first, characteristic of occupational health research, examines the effects of physical aspects of the work environment (e.g., ergonomic design of jobs, exposure to toxic substances) on the prevalence and severity of diseases and syndromes among workers (e.g., Slote, 1987). The next category, characterized by sociological studies, examines how objective (e.g., number of hours worked per week, shift work) and social aspects (e.g., economic adequacy, social prestige) of individuals' jobs affect worker health (e.g., Ross \& Mirowsky, 1995). The final category, distinctive of research in occupational psychology, examines how psychological (e.g., decision latitude, demands) or psychosocial (e.g., relationships with coworkers, workplace culture) features of workers' jobs promote or undermine health and well-being (e.g., Karasek \& Theorell, 1990). The research undertaken in these broad forms generates important empirical and theoretical insights; unfortunately, concepts and findings from these categorically different forms of research seldom cross discipline boundaries.

Warr (1994), however, culled concepts from across disciplines to form a parsimonious yet comprehensive set of "environmental foundations" of jobs that are assumed to underlie the mental health of workers, thereby providing a useful set of salient leverage points for the study of how jobs affect perceived health. Specifically, Warr's environmental foundations of occupational well-being included (a) opportunity for control (e.g., decision latitude), (b) opportunity for skill use (e.g., skill utilization), (c) externally generated goals (e.g., job pressure), (d) variety (e.g., nonrepetitive work), (e) environmental clarity (e.g., information about job and direction), (f) availability of money (e.g., income level), (g) physical security (e.g., safe working conditions), (h) opportunities for interpersonal contact (e.g., quality and quantity of contact with coworkers), and (i) valued social position (e.g., occupational prestige).

In addition to identifying leverage points from 
multiple dimensions of the work environment, social ecological theory also encourages scholars to conceptualize and use multiple levels of analysis within each dimension of the work environment (Stokols, 1996). Many of Warr's (1994) environmental foundations of jobs have manifest and latent forms that can be observed at the level of the individual, asked of the individual, or arrived at by considering the typical level for everyone in that type of job. For example, an individual can be said to have a high opportunity for control if he or she (a) is self-employed versus employed by another, (b) scores higher than the mean on a self-reported scale of decision latitude, or (c) works in a job type characterized by oneself or others as having a high degree of control. Although a substantial body of literature links various aspects of jobs to health-related phenomena, our overall understanding of these linkages remains limited, because most studies use only self-reported evaluations of job control and stress (cf. Karasek et al., 1988; Schwartz, Pieper, \& Karasek, 1988). Our study examines objective (e.g., occupation-based rather than self-reported) as well as subjective measures of work environment, because of the problem (noted in the introduction) of interpreting the effects of self-reported job characteristics.

Following Warr's (1994) general hypotheses linking features of work to mental health, we posed the following hypothetical linkages between different features of jobs assessed at different levels and perceived health effects of jobs. More negative perceptions of the effects of job on health will be correlated with (a) working nights at least once a week, working more than $45 \mathrm{hr}$ per week or at jobs with high perceived job pressure, and working in jobs with high levels of self-reported stress or where a high percentage of workers are required to perform under stress (i.e., high externally generated goals); and (b) working in jobs characterized by high levels of adverse environmental conditions, perceived physical risks, and physical demands on the job (i.e., low physical security).

More positive perceptions of the effects of jobs on health will be correlated with (a) self-employment, higher self-reported decision latitude, and working in jobs in which a high percentage of workers are required to accept responsibility for direction, control, and planning activities (i.e., high opportunities for control); (b) higher self-reported job skills and working in a job requiring a higher level of intelligence aptitude (i.e., high application of skill); (c) working in jobs in which a low percentage of workers are required to perform repetitive work, and individuals in jobs in which a high percentage of workers are required to perform a variety of tasks (i.e., high variation in job content); (d) working in a job paying a higher wage rate (i.e., good availability of money); and (e) working in higher status occupations (i.e., valued social position).

\section{Method}

\section{Data}

The analyses are based on data from the 1995 Mid-Life in the United States (MIDUS) study of noninstitutionalized U.S. residents ages 25-74 years who have telephones, linked to data on occupational characteristics from the Dictionary of Occupational Titles (England \& Kilboume, 1988). The MIDUS survey instruments were developed by the members and associates of the John D. and Catherine T. MacArthur Foundation Network on Successful Mid-Life Development, an interdisciplinary team of researchers, and included information on sociodemographic, psychological, economic, and medical characteristics of the respondent. MIDUS respondents first participated in a random-digit dialing telephone interview lasting approximately $40 \mathrm{~min}$. The response rate for the telephone questionnaire was $70 \%$. Respondents to the telephone survey were then asked to complete two self-administered mailback questionnaires. The response rate for the mailback questionnaire was $87 \%$ of telephone survey respondents, yielding an overall survey response rate of $61 \%$ for both parts of the survey. The sample analyzed here comprised respondents who completed both the telephone and mail surveys and who were working at the time of the interview. A total of 277 respondents were excluded from all analyses because of missing data for outcome measures or personality traits, leaving a sample size of 2,048. Because of missing data, 1 additional respondent was excluded from the regression model with occupation-based job characteristics, and 26 additional respondents were excluded from the model with self-reported job characteristics.

\section{Dependent Variable}

The outcome examined in this study is based on the responses to the following two questions: (a) "Overall, what kind of effect does your job have on your physical health?" and (b) "Overall, what kind of effect does your job have on your emotional or mental health?"2 Response categories were very positive, somewhat positive, neither positive nor negative (or balances out), somewhat negative, and very negative. Respondents with more than one job were instructed to give their best judgment of the combined effect of all jobs.

A substantial body of literature suggests a bidirectional

\footnotetext{
${ }^{2}$ One issue is whether these questions are just another way of looking at job satisfaction. The MIDUS data include a direct measure of job satisfaction; although it is correlated with the responses to these questions, the correlation is far from perfect $(r=.28$ and $r=.36$, respectively, for the impact of job on physical and mental health). Thus, it seems likely that self-reported effects of job on health are measuring a slightly different construct than job satisfaction.
} 
relationship between physical and mental health (Cohen \& Rodriguez, 1995; Patrick \& Erickson, 1993; Ryff \& Singer, 1998; Salovey, Rothman, Detweiler, \& Steward, 2000), with longitudinal studies finding that mental health predicts subsequent physical health outcomes (Fiscella \& Franks, 1997; Levanthal, Hansell, Diefenbach, Leventhal, \& Glass, 1996; Penninx et al., 1998) and physical illness predicts psychological well-being (Berkman et al., 1986; Wickrama, Lorenz, Conger, Matthews, \& Elder, 1997). Thus, the effects of work on mental and physical health are also likely to be inextricably linked. This conjecture is supported by the fact that the distributions of responses to the questions shown above were very similar (see Figure $A l$ in the Appendix) and highly correlated at the individual level ( $\rho=$ .61). Rather than analyzing the responses separately, therefore, we examined whether the worker's responses indicated an unambiguously positive impact of job, for example, if there was a positive effect on physical health and a nonnegative effect on mental health or vice versa $(48 \%$ of the sample); a neutral or mixed effect, for example, negative impact on physical health but positive impact on mental health $(27 \%)$; or an unambiguously negative impact $(25 \%)$.

\section{Independent Variables}

Individual characteristics and resources. Individual demographic characteristics were operationalized using selfreported age (continuous), gender (female $=1$, male $=0$ ), minority status (Black or Hispanic $=1$; White $=0$ ), educational attainment (categorical), marital status (married $=$ 1 ; nonmarried $=0$ ), and parental status to young child (respondent has a child under $6=1$; otherwise $=0$ ).

Individual dispositions were measured using scales of items culled from well-validated personality inventories (for detailed report of specific items, see Lachman \& Weaver, 1997). Perceived constraint was measured with eight items, such as "There is little I can do to change the important things in my life" ( $\alpha=.86)$. Extraversion was measured with five items asking "How well does each of the following describe you?: outgoing, friendly, lively, active, and talkative" ( $\alpha=.78$; Lachman \& Weaver, 1997). Finally, neuroticism was measured with four items asking "How well does each of the following describe you?: moody, worrying, nervous, and calm" ( $\alpha=.74$; Lachman \& Weaver, 1997). The range was 1 (strongly disagree) to 7 (strongly agree) for perceived constraint and 1 (not at all) to 4 (a lot) for extraversion and neuroticism.

Characteristics of respondents' jobs. Self-reports of needing to work nights at least once during an average week and the total number of hours the respondent reported working on all jobs during an average week were used as measures of externally generated job-related demands. Consistent with previous studies (see Ross \& Mirowsky, 1995), we categorized hours spent in paid employment into part time (i.e., less than 35 hr per week), full time (between 35 and $45 \mathrm{hr}$ per week), and more than full time (more than 45 hr per week). Self-employment was used as an indicator of job autonomy or control. The respondent's wage rate was constructed by dividing her or his annual earnings by the annual number of hours worked (calculated as average hours per week times the total weeks worked during the year). The respondent's occupational status was operationalized using a modified Duncan Socioeconomic Index (SEI; Stevens \& Featherman, 1981).
As outlined earlier, several occupation-based measures of respondents' jobs were measured by merging information obtained regarding the respondent's occupation with the Dictionary of Occupational Titles (England \& Kilbourne, 1988). The process yielded scales of the mean adverse environmental conditions, physical demands, and intelligence aptitude in the respondent's occupation. It also yielded the mean percentage of workers in the respondent's occupation (a) accepting responsibility for direction, control, or planning of activity; (b) performing repetitive work or continuously performing the same work according to set procedures, sequence, or pace; (c) performing under stress when confronted with emergency, critical, unusual, or dangerous situations or in situations in which working speed and sustained attention are "make-or-break" aspects of the job; and (d) performing a variety of duties, often changing from one task to another of a different nature without loss of efficiency or composure.

Subjective measures of work environment were obtained from survey questions asking the respondent about serious ongoing stress at work, the extent to which she or he is exposed to the risk of accidents or injuries on the job (recoded as $0=$ not at all, $1=$ a little, $2=$ some, $3=a$ lot), decision latitude, job skills, and job pressure. Decision latitude $(\alpha=.87)$ assessed the amount of control the individual has over his or her work environment. This latent construct was measured by summing responses to four items from the Whitehall II survey (Whitehall Health Survey, 1989), for example, "How often do you have a choice in deciding how you do your tasks at work?" and "How often do you have a choice in deciding what tasks you do at work?" Job skills ( $\alpha=.74)$ were also measured by summing responses to four items revised from the Whitehall II survey, for example, "How often do you learn new things at work?" and "How often does your work demand a high level of skill or expertise?" Job pressure ( $\alpha=.76)$, assessing the amount of psychological strain associated with working, was measured by summing responses to four questions (two from the Whitehall II survey and two that were new to the MIDUS survey), for example, "How often do you have to work very intensively - that is, you are very busy trying to get things done?" and "How often do different people or groups at work demand things from you that you think are hard to combine?" $(\alpha=.76)$. Response categories for each item in these indexes were never $=1$, rarely $=2$, sometimes $=3$, most of the time $=4$, and all of the time $=5$.

\section{Statistical Analysis}

All analyses used sample weights that corrected for differential probabilities of selection and nonresponse to match the age, sex, race, and educational composition of the U.S. population. Owing to the large number of comparisons being made, we used .01 as the cutoff for Type I error in statistical tests. Summary statistics (frequencies for categorical variables and means and standard deviations for continuous variables) were first calculated for the explanatory variables, stratifying the sample by the categorical outcome measure. Differences across groups in the frequency or means are tested using chi-square tests for categorical regressors and analysis of variance for continuous regressors. These results thus show the bivariate (unadjusted) association between the outcome measure and the explanatory variables. 
Ordered logistic regression was then used to estimate the outcome as a function of the individual and job characteristics. Ordered logit models are used to estimate the relationship between an ordered categorical outcome and a set of regressors. A latent index is estimated as a linear function of the regressors and a set of threshold points. The probability of observing outcome $j(j=1, \ldots, J)$ corresponds to the probability that the estimated latent index plus error term is within the range of the thresholds estimated for the outcome:

$\operatorname{Pr}\left(\right.$ outcome $\left._{i}=j\right)$

$$
=\operatorname{Pr}\left(c_{j-1}<\beta_{1} X_{1 i}+\beta_{2} X_{2 i}+\ldots+\beta_{k} X_{k i}+u_{i} \leq c_{j}\right),
$$

where $i$ indexes the individual; $X_{1}, X_{2}, \ldots, X_{k}$ are the $k$ regressors in the model; and the random error term $u_{i}$ is assumed to be logistically distributed. The coefficients $\beta_{1}$, $\beta_{2}, \ldots, \beta_{k}$ are estimated along with the threshold points $c_{1}$, $c_{2}, \ldots, c_{j-1}$, where $c_{0}=-\infty$ and $c_{j}=+\infty$. The estimated effects of job characteristics from the ordered logistic regressions thus control simultaneously for all individuallevel characteristics that may influence the outcome either through perceptions and reporting behavior or because they moderate employment effects on actual health.

Coefficient estimates from logistic regressions are not very informative regarding the magnitude of the effects, so relative risks are also calculated for all statistically significant regressor effects. For dichotomous regressors, the relative risk is calculated as the probability that the value of the outcome falls into the given category when the regressor is set equal to 1 , divided by the probability when the regressor is set equal to 0 . As an example, if minority status ( $1=$ minority, $0=$ nonminority) were associated with relative risks of $0.5,1.0$, and 1.5 for being in the best, middle, and worst outcome categories, respectively, then minorities would be only half as likely as nonminorities to report that jobs have an unambiguously positive impact on their health, about as likely as nonminorities to report mixed effects, and $11 / 2$ times as likely to report that jobs have an unambiguously negative impact on their health. (For continuous regressors, the relative risk is calculated in a similar fashion, but increasing the value of the regressor by one unit above its original mean rather than changing it from 0 to 1 .) Thus, each explanatory variable is associated with a set of three relative risks, one for each of the three outcome categories.

\section{Results}

\section{Descriptive Data and Bivariate Associations}

Table 1 presents the results of the summary statistics and bivariate associations. Compared with workers reporting negative effects of job on health, those who perceived the impact of work on their health to be unambiguously positive were on average significantly older, more likely to be minorities, had lower education, and scored lower on the scales of perceived constraints and neuroticism and higher on the scale of extraversion. They reported greater decision latitude and job skills and less job pressure. They were more likely to be self-employed and to work part time and were less likely to work more than full time, work nights at least once a week, and report serious ongoing stresses at work. Finally, they worked in occupations that had lower SEI scores and required greater physical demands, less repetitive work, and greater intelligence aptitude. Although statistically significant, these latter differences were modest in magnitude.

\section{Ordered Logit Estimates}

Table 2 presents the coefficient estimates, standard errors, and $p$ values from the ordered logit regressions of the self-assessed impact of job on health. Several patterns emerged from these data. Neither sociodemographic characteristics (not shown in the table) nor occupation-based measures of work environment were significantly associated with workers' perceptions of the effect of their jobs on health. In contrast, personality measures, subjective job characteristics, and objective characteristics specific to the worker's own job had strong and significant effects.

In the specification using occupation-based measures of work environment, workers who scored higher on the perceived constraints and neuroticism scales reported less positively about the effects of their job on their health. Conversely, those scoring higher on the extraversion scale reported more positively. These effects were highly significant and fairly large in magnitude. For example, an increase in perceived constraints of one unit above the mean was associated with a 0.92 relative risk of reporting unambiguously positive effects on health, a 0.96 relative risk for reporting mixed or no effects, and a 1.11 relative risk for reporting unambiguously negative effects on health. The comparable sets of relative risks associated with the neuroticism and extraversion scales were, respectively, $0.79,0.89$, and 1.33 and $1.13,1.06$, and 0.84 . Thus, on average, going from the mean on the neuroticism scale to one unit above the mean would decrease the probability of reporting unambiguously positive effects of job on health by about one fifth, decrease the probability of reporting mixed effects by about one tenth, and increase the probability of reporting unambiguously negative effects by one third. When subjective rather than occupation-based job characteristics were controlled for, the effect of perceived constraints is diminished in both magnitude and statistical significance. However, both neuroticism and extraversion retain most of their magnitude and significance. 
Table 1

Weighted Descriptive Data for Mid-Life in the United States Study Workers $(N=2,048)$

\begin{tabular}{|c|c|c|c|}
\hline \multirow[b]{2}{*}{ Worker or job characteristic } & \multicolumn{3}{|c|}{ Workers reporting that job has: } \\
\hline & $\begin{array}{c}\text { Negative effect } \\
\text { on health } \\
(n=535)\end{array}$ & $\begin{array}{l}\text { Mixed or no effect } \\
\text { on health } \\
(n=530)\end{array}$ & $\begin{array}{l}\text { Positive effect } \\
\text { on health } \\
(n=983)\end{array}$ \\
\hline$\%$ female & 48 & 53 & 53 \\
\hline \% married or cohabiting & 75 & 77 & 76 \\
\hline$\%$ with child under age 6 & 21 & 21 & 21 \\
\hline$\%$ minority $^{\mathrm{a}}$ & 15 & 23 & 21 \\
\hline \multicolumn{4}{|l|}{ Education ( 1 = less than high school, } \\
\hline $5={\text { graduate degree })^{\mathbf{a}}}$ & $2.99(1.09)$ & $2.70(1.09)$ & $2.84(1.08)$ \\
\hline $\mathrm{Age}^{\mathrm{a}}$ & $41(10)$ & $42(12)$ & $43(11)$ \\
\hline Perceived constraints (1-7 scale $)^{\mathrm{a}}$ & $2.93(1.12)$ & $2.66(1.21)$ & $2.51(1.19)$ \\
\hline Neuroticism $(1-4 \text { scale })^{\mathrm{a}}$ & $2.47(0.63)$ & $2.28(0.67)$ & $2.16(0.64)$ \\
\hline Extraversion $(1-4 \text { scale })^{a}$ & $3.12(0.54)$ & $3.19(0.57)$ & $3.28(0.55)$ \\
\hline Subjective decision latitude (4-20 scale $)^{a}$ & $13.78(3.44)$ & $14.40(3.95)$ & $15.18(3.42)$ \\
\hline Subjective job skills $(4-20 \text { scale })^{\mathbf{a}}$ & $14.03(2.71)$ & $14.00(3.09)$ & $14.88(2.60)$ \\
\hline Subjective job pressure $(4-20 \text { scale })^{\mathrm{a}}$ & $13.92(2.68)$ & $12.33(2.60)$ & $12.25(2.55)$ \\
\hline \multicolumn{4}{|l|}{$\%$ with serious ongoing stress at work } \\
\hline$(1=\text { yes })^{\mathrm{a}}$ & 71 & 40 & 34 \\
\hline \multicolumn{4}{|l|}{ Perceived exposure to risk of accidents } \\
\hline $4=a(o t)$ & $1.32(1.05)$ & $1.16(1.00)$ & $1.19(1.01)$ \\
\hline \multicolumn{4}{|l|}{$\%$ self-employed ${ }^{2}$} \\
\hline Yes & 13 & 18 & 22 \\
\hline No & 80 & 75 & 71 \\
\hline Missing & 7 & 7 & 7 \\
\hline \multicolumn{4}{|l|}{ Average weekly work hours on all jobs ${ }^{a}$} \\
\hline$\%$ part time $(<35 \mathrm{hr} /$ week $)$ & 10 & 16 & 21 \\
\hline$\%$ full time $(35-45 \mathrm{hr} /$ week $)$ & 47 & 50 & 48 \\
\hline$\%$ more than full time ( $>45 \mathrm{hr} /$ week) & 43 & 33 & 31 \\
\hline \multicolumn{4}{|l|}{ Works nights at least once a week ${ }^{\mathrm{a}}$} \\
\hline$\%$ yes & 21 & 16 & 14 \\
\hline$\%$ no & 72 & 71 & 77 \\
\hline$\%$ missing & 7 & 13 & 9 \\
\hline \multicolumn{4}{|l|}{ Constructed wage rate } \\
\hline$\%$ less than $\$ 10 / \mathrm{hr}$ & 34 & 34 & 39 \\
\hline$\% \$ 10-\$ 17$ dollars $/ \mathrm{hr}$ & 31 & 31 & 27 \\
\hline$\%$ more than $\$ 17 / \mathrm{hr}$ & 30 & 25 & 25 \\
\hline$\%$ missing & 6 & 11 & 9 \\
\hline \multicolumn{4}{|l|}{ Mean adverse environmental conditions } \\
\hline$(0-6$ scale $)$ for occupation & $0.38(0.50)$ & $0.43(0.57)$ & $0.40(0.52)$ \\
\hline \multicolumn{4}{|l|}{ Mean physical demands (0-5 scale) for } \\
\hline \multicolumn{4}{|l|}{$\begin{array}{l}\text { occupation }^{4} \\
\text { Mean intelligence aptitude ( } 1-4 \text { scale })\end{array}$} \\
\hline for occupation ${ }^{2}$ & $2.50(0.56)$ & $2.67(0.62)$ & $2.55(0.60)$ \\
\hline \multicolumn{4}{|l|}{ Duncan Socioeconomic Index for } \\
\hline \multicolumn{4}{|l|}{$\begin{array}{l}\text { occupation } \\
\text { Mean \% of workers in respondent's } \\
\text { occupation requiring adaptability to: }\end{array}$} \\
\hline $\begin{array}{l}\text { Accepting responsibility for direction, } \\
\text { control, or planning of activity }\end{array}$ & $0.32(0.31)$ & $0.27(0.31)$ & $0.31(0.32)$ \\
\hline Performing repetitive work $^{2}$ & $0.16(0.24)$ & $0.21(0.29)$ & $0.15(0.25)$ \\
\hline Performing under stress & $0.08(0.21)$ & $0.06(0.19)$ & $0.06(0.20)$ \\
\hline Performing a variety of duties & $0.46(0.29)$ & $0.44(0.32)$ & $0.48(0.31)$ \\
\hline
\end{tabular}

Note. Numbers in parentheses represent the standard deviation of the mean values.

${ }^{a}$ Denotes that difference across groups is significant at $p \leq .05$. 
Table 2

Ordered Logistic Regressions of Self-Assessed Impact of Job on Health

\begin{tabular}{|c|c|c|c|c|}
\hline \multirow[b]{2}{*}{ Regressor } & \multicolumn{2}{|c|}{$\begin{array}{l}\text { Including occupation-based job } \\
\text { characteristics }(N=2,048)\end{array}$} & \multicolumn{2}{|c|}{$\begin{array}{l}\text { Including self-reported job } \\
\text { characteristics }(N=2,022)\end{array}$} \\
\hline & Coefficient & $p$ & Coefficient & $p$ \\
\hline Perceived constraints & $-0.15(0.04)$ & $<.001$ & $-0.04(0.04)$ & .32 \\
\hline Neuroticism & $-0.42(0.07)$ & $<.001$ & $-0.31(0.08)$ & $<.001$ \\
\hline Extraversion & $0.24(0.08)$ & .003 & $0.23(0.08)$ & .006 \\
\hline Subjective decision latitude & & & $0.15(0.02)$ & $<.001$ \\
\hline Subjective job skills & & & $0.15(0.02)$ & $<.001$ \\
\hline Subjective job pressure & & & $-0.15(0.02)$ & $<.001$ \\
\hline Serious ongoing stress at work & & & $-0.69(0.10)$ & $<.001$ \\
\hline Perceived exposure to risk & & & $-0.005(0.05)$ & .91 \\
\hline Self-employed & $0.45(0.12)$ & $<.001$ & $0.17(0.13)$ & .19 \\
\hline Works part time & $0.45(0.13)$ & $<.001$ & $0.23(0.14)$ & .10 \\
\hline Works more than full time & $-0.37(0.10)$ & $<.001$ & $-0.28(0.11)$ & .008 \\
\hline Works nights at least once a week & $-0.30(0.12)$ & .01 & $-0.31(0.12)$ & .01 \\
\hline Wage rate is $\$ 10-\$ 17 / \mathrm{hr}$ & $-0.31(0.11)$ & .006 & $-0.35(0.11)$ & .002 \\
\hline Wage rate is $>\$ 17 / \mathrm{hr}$ & $-0.42(0.13)$ & $<.001$ & $-0.37(0.13)$ & .004 \\
\hline Duncan Socioeconomic Index & $-0.0001(0.007)$ & .99 & & \\
\hline Adverse environmental conditions ${ }^{\mathrm{a}}$ & $0.01(0.12)$ & .91 & & \\
\hline Physical demands ${ }^{a}$ & $0.10(0.08)$ & .22 & & \\
\hline Intelligence aptitude ${ }^{a}$ & $-0.06(0.15)$ & .71 & & \\
\hline Directing or controlling activity ${ }^{\mathrm{b}}$ & $0.27(0.19)$ & .15 & & \\
\hline Performing repetitive work ${ }^{\mathrm{b}}$ & $0.02(0.24)$ & .94 & & \\
\hline Performing under stress ${ }^{b}$ & $-0.25(0.23)$ & .29 & & \\
\hline Performing a variety of duties ${ }^{b}$ & $0.04(0.17)$ & .80 & & \\
\hline
\end{tabular}

Note. Outcome is defined as $1=$ unambiguously negative effect of job on health, $2=$ mixed or no effect, $3=$ unambiguously positive effect. Coefficients, standard errors (in parentheses), and $p$ values shown. Omitted (comparison) categories for regressors are full-time work and wage rate less than $\$ 10 / \mathrm{hr}$. Regression also controls for sex, age, race, marital status, child under age 6, education, and missing data for wage rate, self-employment, and night shift work.

${ }^{a}$ Measures are mean values for the respondent's occupation. 'b Measures are the mean percentage of workers in the respondent's occupation required to perform the stated task.

Workers who were self-employed ${ }^{3}$ were significantly more likely to report positive effects of their job on their health (and correspondingly less likely to report negative effects) even after controlling for personality traits and other individual traits associated with differential perceptions regarding health status. In the specification using occupation-based measures of work environment, the relative risks associated with self-employment were $1.25,1.11$, and 0.72 , suggesting, for instance, that workers are $25 \%$ more likely to report that their job is good for both their mental and physical health if they are self-employed. The self-employment effect was reduced and lost statistical significance in the specification using subjective job characteristics, suggesting that part of the association of self-employment with perceived job effects on health is mediated by job characteristics such as decision latitude, job skills, and job pressures.

Working nights at least once a week and working more than full time were both strongly associated with less positive reporting of job effects on health. This was true regardless of whether the specification included occupation-based or subjective measures of work environment. (In the first specification, working part time was also significantly associated with more positive reporting of job effects on health.) In the specification with occupation-based measures, the relative risks associated with working the night shift were $0.85,0.92$, and 1.23 and the relative risks associated with working more than full time were 0.82 , 0.92 , and 1.24; that is, both people working the night

\footnotetext{
${ }^{3}$ We cannot entirely rule out that the positive effect of self-employment is due to self-selection of people with particular characteristics conducive both to self-employment and to positive perceptions of job effects on health. However, this result controls for the Big Three personality traits, and the estimates were virtually identical in specifications that controlled for additional traits, such as sense of mastery and agency, openness, agreeableness, and conscientiousness.
} 
shift and those working more than full time were about one quarter more likely to report unambiguously negative effects of work on health.

Workers earning more than $\$ 10$ per hour reported less positive effects of their job on their health than workers earning less than $\$ 10$ per hour, and the effects again retained their magnitude and significance in both specifications. In the first specification, the relative risks associated with having a wage rate between $\$ 10$ and $\$ 17$ instead of a wage rate of under $\$ 10$ were $0.85,0.92$, and 1.24 . The effects of having a wage rate over $\$ 17$ were even larger, with relative risks of $0.80,0.89$, and 1.33 . Thus, for example, whereas workers with wage rates between $\$ 10$ and $\$ 17$ were only $15 \%$ less likely to report positive effects of work on health, those with wage rates over $\$ 17$ were $20 \%$ less likely to report such effects.

As expected, workers who reported greater decision latitude and job skills were also more likely to report positive effects of their job on their health, whereas those who reported higher job pressure and serious ongoing stress at work were less likely to report positive effects. The relative risks associated with the subjective decision latitude scale were 1.03 , 1.01 , and 0.97 ; with the subjective job skills scale, $1.14,1.11$, and 0.96 ; and with the subjective job pressure scale, $0.92,0.96$, and 1.10 . The effects of reporting serious ongoing stress at work were particularly large, with relative risks of $0.69,0.84$, and 1.60. Thus, a worker reporting serious ongoing stress at work would be only about two thirds as likely to report positive effects of job on health, but about two thirds more likely to report negative effects, as a worker who did not report such stress.

\section{Discussion}

This study took a unique approach to studying the work-health relationship by examining the correlates of workers' ratings of how their job affects their health. About half of the workers reported an unambiguously positive impact of their job on their health (considering effects on both mental and physical health). The remainder were about evenly divided between those reporting no impact or a mixed effect and those reporting an unambiguously negative effect. The generally positive perceptions of how the workers' jobs affect their health are consistent with the general pattern of optimism previously noted among the MIDUS sample (Lachman \& Weaver, 1998), as well as the high demand for labor experienced in the mid- to late 1990s, which may have led to workers' obtaining unusually good jobs. It may also be that workers who perceive that their jobs are exceptionally bad for their health end up switching jobs, so that a "snapshot" picture of the labor force finds most people in jobs they perceive to be good for their health.

Consistent with the ecological premise that both person and environment factors shape individual experiences, we found that both individual personality characteristics and objective and subjective features of the individual's job were robust correlates of workers' perceptions of how their jobs affect their health. Specifically, workers with higher levels of perceived constraints and neuroticism and a lower level of extraversion were more likely to report that their job undermines their health (and correspondingly less likely to believe that their work has a positive effect on their health). Individuals who worked nights or more than $45 \mathrm{hr}$ per week (compared with 35-45 hr) were more likely to report that their job undermines their health. Respondents who were self-employed or who worked less than $35 \mathrm{hr}$ per week were more likely to have favorable perceptions of how their work affects their health, although these associations were no longer significant after controlling for subjective job characteristics. Workers who reported holding jobs with various positive attributes (and fewer negative attributes) were also more likely to report positive effects of their jobs on their health; however, it is possible that this association is due in large part to common reporting bias, that is, the fact that some respondents report more positively about their experiences in the world than others.

The strength and magnitude of these findings are even more compelling, given that our data and model allow for only a limited application of the ecological framework. Unfortunately, complexity is the biggest limitation of using an ecological framework for studying the linkages between work and health (Green, Richard, \& Potvin, 1996). Indeed, a more comprehensive ecological model would require multiple types (e.g., self-report and observational), sources (e.g., individual, coworker, and occupation-based), and levels (e.g., worker, worker-supervisor dyad, and job level) of data to obtain a richer view of the individual in the context of work. Additionally, the empirical model and corresponding analyses would require inclusion of large numbers of interaction terms to adequately assess the impact of "ecological transitions" (Bronfenbrenner, 1979) and different person-environment interactions relevant to health. In this study, the data provided only self-report and occupation-based data, and we incorporated only a small portion of the possible interaction terms to 
avoid the potential of overfitting the model. Future research can build on these modest beginnings to develop a more comprehensive ecological model of the linkages between work and health.

Several of our hypotheses regarding how individual and employment characteristics would influence workers' perceptions of how their job affects their health were not supported, however. None of the individual-level "social address" characteristics were correlated with our outcomes. The absence of robust associations between occupation-based job characteristics and perceptions of how work influences health is also noteworthy. These null findings could be interpreted in several ways. The most apparent explanation is the unknown (presumably large) amount of error associated with these measures that might have obscured actual associations. Similarly, occupation-based measures of employment features may not be sensitive enough to individual employment contexts to shape perceptions of how work affects health in a meaningful way, although they have been found to influence discrete health outcomes (e.g., Karasek et al., 1988; Schwartz et al., 1988). This possibility is likely to be especially pronounced in our relatively homogeneous sample of white-collar workers employed in jobs that are arguably most satisfying. The objective features of the individual's own job that were used in this study may come closer to the actual lived experience of the workers in this sample. Admittedly, however, working long or odd hours or being self-employed is very likely tapping other, more important, experiences of work, such as work-family strain (e.g., Barnett, 1998) or in the latter case, greater decision latitude (as was demonstrated in our analyses containing self-reported job characteristics).

It is also important to note that some of our findings actually contradict our expectations. For example, results indicating that higher wages lead to more negative perceptions of how work affects health run counter to related literature linking wages or income, as an indicator of socioeconomic status, to health (e.g., Adler et al., 1994; Marmot, Kogevinas, \& Elston, 1987), as well as research linking wages to occupational well-being (e.g., Warr, 1992). This pattern is difficult to interpret. Our outcomes may be tapping a general sense of "control over health." Higher status individuals, in terms of income and education, generally have stronger feelings of control over their health (e.g., Lachman \& Weaver, 1998), which may lead them to be more likely to report no impact of work on health rather than a positive impact. Alternatively, hourly wage may be tapping some aspect of work that is not otherwise adequately measured, such as the relative level of stress or work-nonwork strain (Greenhaus \& Parasuraman, 1986) associated with the individual's job. These findings are compelling and deserving of future research.

Our results should be interpreted with caution, given certain study limitations. For example, the question arises of whether our outcome measure is capturing true effects of job on health or just perceptions. The measure itself is an amalgam of the two; however, to the extent that we are able to control for the individual traits influencing the worker's outlook on life (e.g., the fact that neurotic people are more likely to see themselves as sick, even when they are not), the estimated effect of the objective job characteristics on the outcome measure should capture some aspect of true health effects. The Big Three personality traits were strongly associated with the outcome measure, suggesting that our personality measures are capturing an important component of the variation attributable to people's perceptions.

If we are unable to perfectly adjust for personality, then the estimated effect of objective job characteristics correlated with personality may be biased. The best example is self-employment, because people who select into self-employment may have different personality traits from other workers. Although we cannot entirely rule out the possibility of bias, regression specifications controlling for additional respondent traits (sense of mastery and agency, openness, agreeableness, and conscientiousness) yielded almost identical results, suggesting that even if we had further controls for personality, the results would be robust.

Perhaps the strongest evidence of the impact of objective job characteristics is provided by the second regression specification. By controlling simultaneously for subjective job characteristics, we eliminated the portion of the variance that results from common reporting bias in both perceived job characteristics and perceived effects of job on health. In other specifications not shown here, we also controlled for the person's self-reported mental and physical health (which should also be strong proxies for the person's tendency to report negatively about his or her health) and found virtually the same results for the objective job characteristics. Our interpretation of the results of all of these sensitivity analyses is that, to a large extent, the estimated effects of the objective job characteristics from the multiple regression models may 
reflect variation in the effects of work on true, rather than perceived, health. ${ }^{4}$

In light of the National Occupational Research Agenda, the results from this study generate some compelling implications for policy, employment practice, and future research. The large, robust association found in this study between working nights or longer hours and more negative reported effects of work on physical and mental health is particularly striking, given modern workplace realities requiring longer hours and more shift work (NIOSH, 1996). To the extent that self-reported effects of the job on health are linked to objective health experiences (e.g., Rasanen, Notkola, \& Husman, 1997), policies related to job design would need to recognize that some jobs may promote individual and community health, whereas others may undermine health and well-being. For example, when a company is faced with decisions to meet production demands in the workplace, running "lean and mean" could have unseen costs that might be avoided by allowing workers to avoid working chronic overtime and hiring additional temporary help. Similarly, economic policies providing community supports and resources for the development and viability of self-employment might generate greater capacity for building individual and community health than alternative plans designed to attract out-of-state businesses that frequently offer a disproportionately large number of low-level jobs. Finally, one important extension of this study would be to examine how self-employment differs from working for others, to determine whether such characteristics (e.g., flexible work hours) could be emulated by companies seeking to improve the health of their workers.

\section{Conclusions}

Work and health are intimately connected, yet the complex association is not well understood, because features of both the employee and the employment context influence worker well-being. By asking employees themselves how their work affects their health and well-being, we gain a different, important perspective on the work-health relationship. Although enduring aspects of personality were clearly associated with the perceived effects of work on health, so too were malleable features of the work environment. The results from this study and similar studies provide employers as well as policymakers with the information and perhaps the motivation to improve working conditions and to create jobs that have lasting health benefits, not only to the worker but also to the larger community to which they belong.

${ }^{4}$ Note that to the degree that the worker's overall health status is determined by mental health, which is largely subjective to begin with, the perceived effects of job on health by definition reflect true health effects.

\section{References}

Adler, N. E., Boyce, T., Chesney, M. A., Cohen, S., Folkman, S., Kahn, R. L., \& Syme, S. L. (1994). Socioeconomic status and health: The challenge of the gradient. American Psychologist, 49, 15-24.

Barnett, R. C. (1998). Toward a review and reconceptualization of the work/family literature. Genetic, Social and General Psychology Monographs, 124, 125-182.

Berkman, L. F., Berkman, C. S., Kasl, S., Freeman, D. H., Leo, L., Ostfeld, A. M., Comoni-Huntley, J., \& Brody, J. A. (1986). Depressive symptoms in relation to physical health and functioning in the elderly. American Journal of Epidemiology, 124, 372-388.

Bronfenbrenner, U. (1979). The ecology of human development: Experiments by nature and design. Cambridge, MA: Harvard University Press.

Bronfenbrenner, U., \& Morris, P. A. (1998). The ecology of developmental processes. In W. Damon (Ed.), Handbook of child psychology (5th ed., Vol. 1, pp. 993-1028). New York: Wiley.

Campbell, D. T. (1969). Ethnocentrism of disciplines and the fish-scale model of omniscience. In M. Sherif \& C. W. Sherif (Eds.), Interdisciplinary relationships in the social sciences (pp. 328-348). Chicago: Aldine Press.

Cohen, S., \& Rodriguez, M. S. (1995). Pathways linking affective disturbances and physical disorders. Health Psychology, 14, 374-380.

Costa, P. T., Jr., \& McCrae, R. R. (1988). Personality in adulthood: A six-year longitudinal study of self-reports and spouse rating on the NEO Personality Inventory. Journal of Personality and Social Psychology, 54, 853 863.

Curtis, A. B., James, S. A., Raghunathan, T. E., \& Alcser, K. H. (1997). Job strain and blood pressure in African Americans: The Pitt County Study. American Journal of Public Health, 87, 1297-1302.

Dooley, D., Fielding, J., \& Levi, L. (1996). Health and unemployment. Annual Review of Public Health, 17, 449-465.

England, P., \& Kilbourne, B. (1988). Occupational measures from the Dictionary of Occupational Titles for the 1980 census detailed occupations (Codebook ICPSR 8942) [data archive]. (Available from the Inter-University Consortium for Political and Social Research, 426 Thompson Street, Ann Arbor, MI 48104-2321)

Feather, N. T. (1990). The psychological impact of unemployment. New York: Springer-Verlag.

Fiscella, K., \& Franks, P. (1997). Does psychological distress contribute to racial and socioeconomic disparities in mortality? Social Science and Medicine, 45, 1805-1809.

Goode, W. J. (1960). A theory of role strain. American Sociological Review, 25, 483-496.

Green, L. W., Richard, L., \& Potvin, L. (1996). Ecological foundations of health promotion. American Journal of Health Promotion, 10, 270-281. 
Greenhaus, J. H., \& Parasuraman, S. (1986). A worknonwork interactive perspective of stress and its consequences. Journal of Organizational Behavior Management, 8, 37-60.

Hallquist, J., Diderichsen, F., Theorell, T., Reuterwall, C., Ahlbom, A., \& SHEEP Study Group. (1998). Is the effect of job strain on myocardial infarction risk due to interaction between high psychological demands and low decision latitude? Results from the Stockholm Heart Epidemiology Program (SHEEP). Social Science and Medicine, 46, 1405-1415.

Haynes, C. E., Wall, T. D., Bolden, R. I., Stride, C., \& Rick, J. E. (1999). Measures of perceived work characteristics for health services research: Test of a measurement model and normative data. British Journal of Health Psychology, 4, 257-275.

Haynes, S. G. (1980). Women, work and coronary heart disease: Prospective findings from the Framingham Heart Study. American Journal of Public Health, 70, 133-141.

Jahoda, M. (1982). Employment and unemployment: A social-psychological analysis. Cambridge, England: Cambridge University Press.

Karasek, R. (1990). Lower health risk with increased job control among white collar workers. Journal of Organizational Behaviour, 11, 17 $1-185$.

Karasek, R. A., \& Theorell, T. (1990). Healthy work: Stress, productivity, and the reconstruction of working life. New York: Basic Books.

Karasek, R. A., Theorell, T., Schwartz, J. E., Schnall, P. L., Pieper, C. F., \& Michela, J. L. (1988). Job characteristics in relation to the prevalence of myocardial infarction in the US Health Examination Survey (HES) and the Health and Nutrition Examination Survey (HANES). American Journal of Public Health, 78, 910-918.

Kasl, S. V., Rodriguez, E., \& Lasch, K. E. (1998). The impact of unemployment on health and well-being. In B. P. Dohrenwend (Ed.), Adversity, stress, and psychopathology (pp. 111-131). New York: Oxford University Press.

Lachman, M. E., \& Weaver, S. L. (1997). The Midlife Development Inventory (MIDI) personality scales: Scale construction and scoring (Tech. Rep. No. 1). Waltham, MA: Brandeis University, Department of Psychology.

Lachman, M. E., \& Weaver, S. L. (1998). The sense of control as a moderator of social class differences in health and well-being. Joumal of Personality and Social Psychology, 74, 763-773.

Levanthal, E. A., Hansell, S., Diefenbach, M., Leventhal, H., \& Glass, D. C. (1996). Negative affect and self-report of physical symptoms: Two longitudinal studies of older adults. Health Psychology, 15, 193-199.

Marnot, M. G., Kogevinas, M., \& Elston, M. A. (1987). Social/economic status and disease. Annual Review of Public Health, 8, 111-135.

National Institute of Occupational Safety and Health. (1996). National occupational research agenda (DHHS Publication No. NIOSH 96-115). Washington, DC: U.S. Government Printing Office.

Patrick, D. L., \& Erickson, P. (1993). Health status and health policy: Quality of life in health care evaluation and resource allocation. New York: Oxford University Press.

Penninx, B. W. J. H., Guralnik, J, M., Ferrucci, L., Simonsick, E. M., Deeg, D. J. H., \& Wallace, R. B. (1998). Depressive symptoms and physical decline in commu- nity-dwelling older persons. Joumal of the American Medical Association, 279, 1720-1726.

Rasanen, K., Notkola, V., \& Husman, K. (1997). Perceived work conditions and work-related symptoms among employed Finns. Social Science and Medicine, 45, 1099-1110.

Repetti, R. L., Matthews, K. A., \& Waldron, I. (1989). Employment and women's health: Effects of paid employment on women's mental and physical health. American Psychologist, 44, 1394-1401.

Ross, C. E., \& Mirowsky, J. (1995). Does employment affect health. Journal of Health and Social Behavior, 36, 230-243.

Ryff, C. D., \& Singer, B. (1998). The contours of positive human health. Psychological Inquiry, 9, 1-28.

Salovey, P., Rothman, A. J., Detweiler, J. B., \& Steward, W. T. (2000). Emotional states and physical health. American Psychologist, 55, 110-121.

Schnall, P. L., Schwartz, J. E., Landsbergis, P. A., Warren, K., \& Pickering, T. G. (1998). A longitudinal study of job strain and ambulatory blood pressure: Results from a threeyear follow-up. Psychosomatic Medicine, 60, 697-706.

Schwartz, J. E., Pieper, C. F., \& Karasek, R. A. (1988). A procedure for linking psychosocial job characteristics data to health surveys. American Journal of Public Health, 78, 904-909.

Slote, L. (1987). Handbook of occupational safety and health. New York: Wiley.

Smith, T. W. (1992). Hostility and health: Current status of a psychosomatic hypothesis. Health Psychology, 11, 139150.

Stevens, G., \& Featherman, D. L. (1981). A revised socioeconomic index of occupational status. Social Science Research, 10, 364-395.

Stokols, D. (1992). Establishing and maintaining healthy environments: Toward a social ecology of health promotion. American Psychologist, 47, 6-22.

Stokols, D. (1996). Translating social ecological theory into guidelines for community health promotion. American Journal of Health Promotion, 10, 282-298.

Tausig, M., \& Fenwick, R. (1999). Recession and wellbeing. Journal of Health and Social Behavior, 40, 1-16.

Theorell, T., Tsutsumi, A., Hallquist, J., Reuterwall, C., Hogstedt, C., Fredlund, P., Emlund, N., \& Johnson, J. V. (1998). Decision latitude, job strain, and myocardial infarction: A study of working men in Stockholm. American Journal of Public Health, 88, 382-388.

U.S. Department of Labor. (1999). Employment and earnings (Vol. 39, Whole issue). Washington, DC: U.S. Govemment Printing Office.

Warr, P. B. (1992). Age and occupational well-being. Psychology and Aging, 7, 37-45.

Warr, P. B. (1994). A conceptual framework for the study of work and mental health. Work \& Stress, 8, 84-97.

Watson, D., \& Hubbard, B. (1996). Adaptational style and dispositional structure: Coping in the context of the FiveFactor model. Journal of Personality, 64, 737-774.

Whitehall Health Survey. (1989). Department of Community Medicine, University College of London, and Civil Service Occupational Health Service (Version 2). London: University College of London.

Wickrama, K. A. S., Lorenz, F. O., Conger, R. D., Mat thews, L., \& Elder, G. H. (1997). Linking occupational conditions to physical health through marital, social and intrapersonal processes. Journal of Health and Social Behavior, 38, 363-375. 


\section{Appendix}

Self-Assessed Impact of Job on Physical and Mental Health Among Workers Aged 25-74

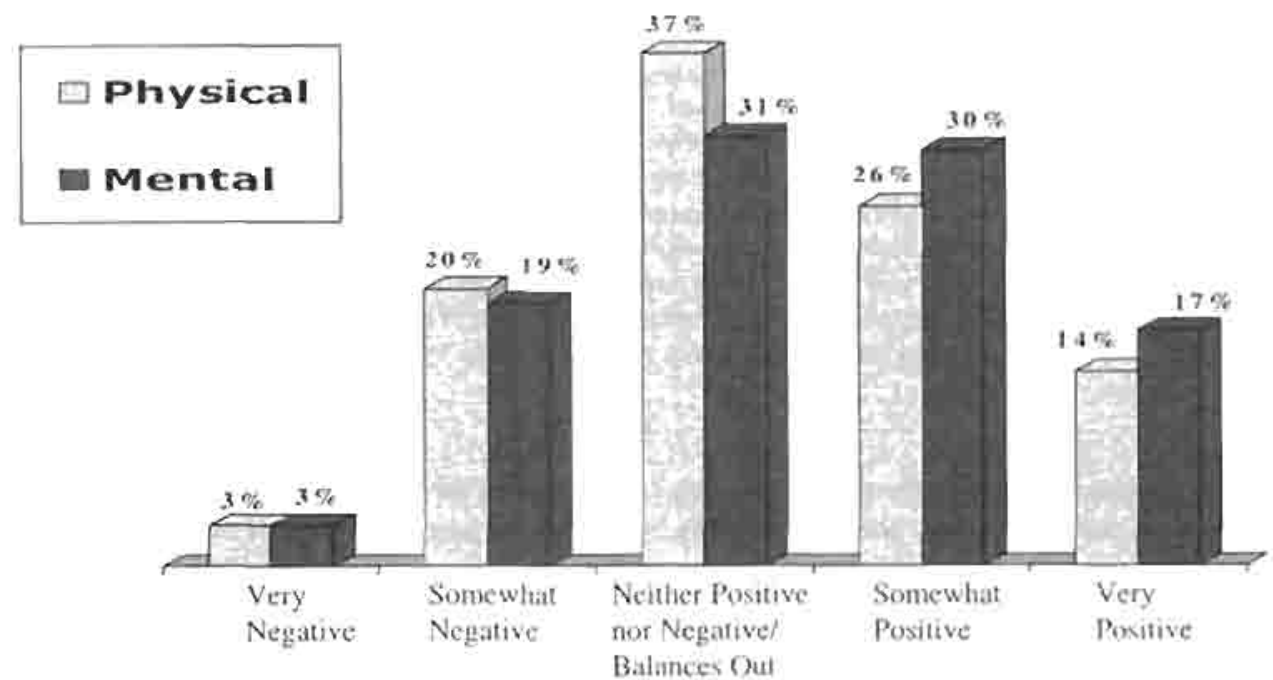

Figure Al, Data from 1995 Mid-Life in the United States Study $(N=2048)$.

Received December 14. 1999 Revision received Seplember 6.2000 Accepted September 9. 2000 